\title{
Taking Immersion home
}

\section{Applying lessons learned at ACRL's Immersion Program}

\author{
by Marie Garrett
}

$\mathrm{E}$ ach year ACRL's Institute for Information Literacy sponsors the Immersion Program to train librarians in their roles as teachers and coordinators of information literacy programs. ${ }^{1}$ Immersion faculty provide a rich, intense learning experience; participants depart with information, ideas, and enthusiasm. But what exactly does one do with this fout-and-a-half day investment in education? Each participant will answer this question differently as each institution requires unique approaches. In sharing my experience, I hope to inspire interest in the Immersion program, to encourage others to share their experiences, and to spark ideas that may take root and flourish elsewhere.

I attended the Wisconsin Immersion program at Edgewood College in June 2001. As instructional services coordinator with the University of Tennessee (UT') Libraries, I enrolled in Track 2 for program developers. My colleague, Jacqueline Kracker, attended the August 2001 national program at Plattsburgh State University of New York. As a new librarian, she chose Track 1 for teachers. The program equipped us for building information literacy into our teaching and instructional programs. Our collaboration afterward strengthened the quality of the information literacy workshops we developed for our UT colleagues and provided encouragement along the way.

Back at UT after completing the Immersion Program, my initial priority was to create a culture of information literacy within the library in preparation for engagement in campus-wide information literacy initiatives. With the support of Rita Smith, head of reference and instruc- tional services, four reference department meetings during the fall of 2001 were devoted to information literacy. Kracker and I planned and presented four workshops based on the Immersion curriculum, distilling four-and-a-half days into four-and-a-half hours. The sessions progressed from exploring information literacy concepts to experiencing the practice of incorporating it into our teaching to generating ideas for outreach on campus. We encouraged all interested library staff to attend.

For the first session, "Exploring What Information Literacy Is and What it Means to Us," we asked participants to read a brief article from the Teacher Librarian titled "Competency Standards for Higher Education" ${ }^{2}$ and to review our own recently created information literacy Web site. ${ }^{3}$ Smith introduced the series by providing the UT context for this initiative. We asked attendees to describe a person who uses information effectively or to list characteristics of an information literate person. Together, we explored the various aspects of information literacy, discussed how the concept fits into our work, and examined how our current teaching endeavors fit into information literacy.

The next two sessions focused on assessment. In "Taking Information Literacy into the Classroom, Part I: Leaming Outcomes and Assessment," we defined learning outcomes and discussed assessment as student learning. Working in small groups with the competency standards, we practiced the process of asking what we teach and why and what students learn as a result, changing our approach based on this information." We also

\section{About the author}

Marie Garrett is instructional services coordinator at the University of Tennessee Libraries, e-mail: mgarrett@utk.edu 
presented some classroom assessment techniques. As background for this session, attendees read Mark Battersby's "So What's a Learning Outcome Anyway?"

In "Taking Information Literacy into the Classroom, Part II: Putting Assessment into Practice," workshop participants built on a homework assignment given during a previous session. Each instructor selected an instructional situation and identified learning outcomes, designed an assessment, and developed criteria for judging the results. We shared observations about the process and discussed how our teaching might change because of our experience with assessment. Instructors who had tried assessment techniques following the initial assessment workshop shared their experiences.

From the classroom, we moved to a broader context. Our concluding session, "Taking Information Literacy to the University Community: Extending Our Vision," explored making the transition from bibliographic instruction to information literacy and forming partnerships with fac ulty. Barbara Dewey, dean of the libraries, presented her vision for information literacy on the UT campus and encouraged us in our outreach to faculty. With Patricia Iannuzzi's article "Faculty Development and Information Literacy: Establishing Campus Pattnerships" as background, we identified "hot initiatives" on the UT campus. The program concluded with a brief overview of future plans for our information literacy efforts.

Following the workshops, six librarians joined me in forming an Information Literacy Planning Group. In the spring of 2002, we developed a new mission statement for Instructional Services as a context for our work and a one-year information literacy plan. We also drafted a long-range information literacy plan, seeking library-wide input. Recently, we sponsored a library-wide contest to find an information literacy slogan or logo. The winning entry highlights a redesign for our information literacy brochure targeted to acquaint faculty, adiministrators, and students with overall information literacy concepts and to publicize UT's information literacy initiative.

The goals outlined in our one-year plan led to the formation of three working groups: a faculty partnerships working group to promote information literacy concepts with faculty and to facilitate partnerships; a foundational skills group to re-envision our work with the freshman composition program and to create foundational tutorials for information literacy; and a campus partner- ships group to identify and facilitate partnerships with appropriate groups and organizations on campus. Two people from the initial planning group lead each of the working groups. The work of these teams draws upon the expertise of subject librarians throughout the libraries and broadens the outreach of the program. As we widen our involvement, we continue to expand and refine our approach to integrating information literacy into the campus culture.

Our outreach to faculty will build on a series of well-publicized workshops for faculty and graduate students throughout the fall semester. We also plan to sponsor focus groups or faculty round tables, to increase our publicity efforts, and to host a reception for new faculty in the spring. Subject librarians have helped us identify potential faculty partners, and as our efforts expand, we will invite faculty representatives to join us in our planning.

Our ultimate goal focuses on enhancing student learning —on helping equip students with information skills and abilities that will benefit them in the academic world and beyond, throughout their work and life experiences. At times the process seems to move slowly on this large university campus, but we make steady progress toward building a strong foundation for information literacy efforts. The recent appointment of our head of reference to the campus General Education Committee positions us well to partner with faculty in integrating information literacy into the undergraduate curriculum.

Our experience thus far leads me to offer these words of encouragement for others who seek to engage librarians, faculty, and students in developing information literacy programs:

- Recognize that building an information literacy program takes time, persistence, and patience, and believe that you will see good results from your efforts.

(continued on page 609)

\section{Apply for Immersion '04}

Immersion ' 04 will be held at the University of Washington, July 30-August 4, 2004. The Invitation to Apply is available online at www.acrl.org/immersion; the deadline to apply is December 5, 2003. Immersion '04 is limited to 90 individuals and acceptance to the program is competitive. 


\section{NEW FROM OXFORD}

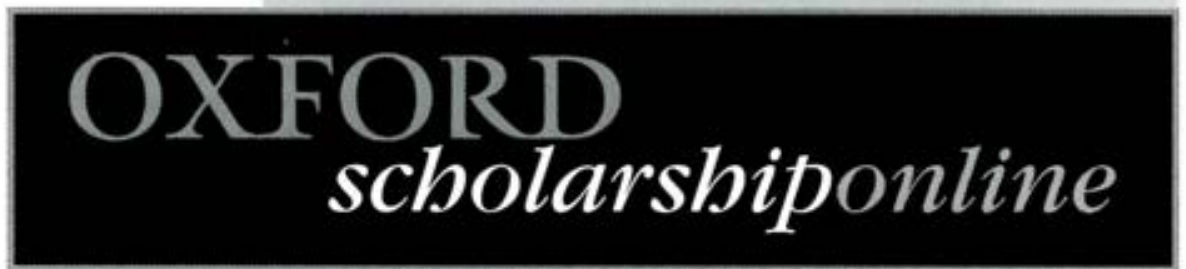

www.oxfordscholarship.com

ver 700 classic and newly-published Oxford mono-
graphs will now be fully cross-searchable online, with over 200 new titles added each year. Four subject collections will feature the best scholarly books in:

- Philosophy - Political Science

- Religion - Economics \& Finance

Specially commissioned keywords, book and chapter abstracts for each book, and reference linking from bibliographies and footnotes to online content make this a powerful and unique research tool for scholars and students.

Oxford Scbolarsip Online is available by annual subscription as a complete resource or by individual subject collections.

Full listings of the books available at launch and an online demonstration are available at www.oxfordscholarship.com

For pricing information or to register for a free 30-day trial, please contact onlinesubscriptions@oup-usa.org or call 800-334-4249 ext. 6484.

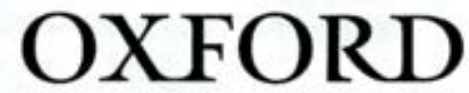

UNIVERSITY PRESS 
Just as important, the e-selection tools proved to be good marketing and public relations mechanisms for the library. Our library is perceived as a campus technology leader, a place where the staff continuously explores new tools and technologies to improve existing resources and services to better serve our constituents. The benefits from using the tools are both tangible and intangible: wiser selections leading to improved collections, improved faculty-librarian communication, greater understanding, and deeper collaboration.
E-selection tools can yield a high return with a minimal investment for an academic library of any size or collection scope. Having fewer or no paper selection cards to deal with is an added bonus about which few librarians or faculty can complain.

\section{Note}

1. Operational details, screen shots, and descriptive notes are provided at staff.philau.edu/ bells/eselect.htm.

\section{("Taking Immersion bome," continued from page 588)}

- Focus on the long-term goal while celebrating successes along the way.

- Begin with a small group of people and work toward incorporating a variety of ideas and talents from a variety of groups.

- Build on the expertise and strengths of veteran librarians and draw upon the enthusiasm and new ideas of new librarians.

- Keep your focus on students and on their learning.

- Share your experience with others.

I wish each of you well with your information literacy initiatives on campuses large and small. Students will benefit from your creativity, caring, and perseverance.

Thank you to the Immersion faculty ${ }^{8}$ for your commitment to creating quality educational experiences for librarians who teach. Thank you to ACRL for sponsoring this national program each year and to the Wisconsin Association of Academic Librarian's Information Literacy Committee for sponsoring the 2001 regional program. Immersion ' 01 provided a learning experience well worth taking home.

\section{Notes}

1. For more information, see www.acrl. org/inmersion.
2. Association of College and Research Libraries, "Competency Standards for Higher Education," Teacber Librarian 28.3 (Feb. 2001): 16-18.

3. Visit the University of Tennessee's information literacy Web site at www.lib.utk.edu/instruction/infolit/infolit.html.

4. Based on Debra Gilchrist's presentation, "Improving Student Learning."

5. From Angelo, Thomas A. and K. Patricia Cross. Classroom Assessment Techniques: AHandbookfor College Teachers. 2nd ed. San Francisco: Jossey Bass, 1993.

6. Mark Battersby and the Leaming Outcomes Network, "So What's a Learning Outcome Anyway?" Vancouver, B.C.: Centre for Curriculum, Transfer, and Technology. Available at www.c2t2. $\mathrm{ca} /$ page.asp?item_id=394\&path=

7. Patricia Iannuzzi, "Faculty Development and Information Literacy: Establishing Campus Partnerships," Reference Services Review (Fall) Winter 1998): 97-102, 116.

8. The Immersion faculty: Craig Gibson, George Mason University; Debra Gilchrist, Pierce College; Randy Burke Hensley, University of Hawaii-Manoa; Beth S. Woodard, University of Illinois at Uıbana-Champaign; and Anne E. Zald, University of Washington.

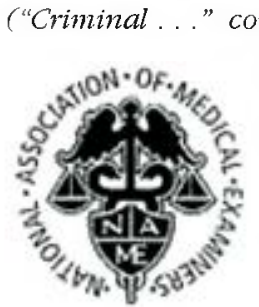
only offers four sites. Access: www. thename.org/.

\section{Notes}

1. Madeleine R. Nash and Richard L. Faraino, "Internet Resources in Legal Medicine and Forensic Science," Medical Reference Services Quarterty 18.1 (Spring 1999): 59-68.

2. Cynthia Holt, "Forensic Science Resources on the Internet" Issues in Science and Technology Librarianship 37 (2003) [cited 1 September 2003]. Available on the Web at www.istlorg/03-spring/ internet.html.

3. Ibid. 